\title{
A educação sobre drogas e as limitações do paradoxo da indústria da cerveja
}

\begin{abstract}
Resumo: Este estudo se baseia em uma releitura da educação sobre drogas a fim de problematizar as limitações a essa abordagem nas estratégias educativas da indústria de bebidas, mais especificamente, a indústria da cerveja. Em um escopo mais amplo, a pesquisa se desenvolveu no Centro de Experiência Cervejeira da Bohemia (CECB) que pertence à Companhia de Bebidas das Américas (Ambev), localizado na cidade de Petrópolis, no estado do Rio de Janeiro. O objetivo deste artigo foi analisar a cartilha Papo em família: como falar sobre bebidas alcoólicas com menores de 18 anos distribuída aos responsáveis de menores de 18 anos em visita ao tour cervejeiro do CECB. A questão sobre a qual nos debruçamos se refere a compreender os dispositivos que interferem na produção de significados sobre o uso do álcool na cartilha e sua relação com a educação sobre drogas na perspectiva da autonomia, buscando identificar os dispositivos que atuam na limitação dessa abordagem. Como resultado sugerimos a existência de um paradoxo da indústria da cerveja no qual por um lado a Ambev estimula o uso do álcool, e por outro, adota uma abordagem proibicionista, o que se deve a tensionamentos entre interesses mercadológicos e dispositivos médico-legais, retroalimentados pela política de guerra às drogas.
\end{abstract}

Palavras-chave: educação sobre drogas; álcool; indústria de bebidas; cerveja; dispositivos médico-legais.
Renato Augusto Silva Monteiro Universidade Federal do Rio de Janeiro

renatomonteiro.ufrj@gmail.com

\section{Introdução}

Este estudo advém de uma pesquisa de doutoramento em Educação em Ciências e Saúde, que analisou as mediações socioculturais no Centro de Experiência Cervejeira da Bohemia (CECB), que se caracteriza como a unidade de produção de cerveja da marca Bohemia que pertence à Companhia de Bebidas das Américas (Ambev). A cidade de Petrópolis está localizada na região serrana do estado do Rio de Janeiro e é conhecida por possuir importantes atrativos turísticos culturais como o Museu Imperial, antiga residência de veraneio da família imperial portuguesa. A pesquisa, em escopo mais amplo, teve como objetivo analisar a mediação nas salas de exposição do CECB, entendendo esse espaço como um centro de divulgação de ciência e tecnologia de caráter privado, o que destoa da maior parte dos museus de ciência e tecnologia no Brasil, que tiveram seu desenvolvimento advindo de esforços 
públicos do processo de redemocratização do país na década de 1980. (VALENTE, 2009)

Embora os resultados de pesquisa que trazemos não digam respeito diretamente à análise inicial, fazem parte de um desdobramento de questões que surgiram ao longo da pesquisa de campo e que levaram à análise de uma cartilha sobre o uso do álcool que era distribuída aos responsáveis de menores de 18 anos que visitavam o local. O CECB é um espaço de divulgação da cultura e do processo de produção da cerveja que propõe ao visitante uma experiência no tour cervejeiro, um percurso que dura em média uma hora e meia para ser percorrido. A visitação ocorre por meio de salas de exposição nas quais o visitante interage com diversos aparatos que abordam aspectos da história, dos ingredientes e do processo de produção da cerveja.

A questão sobre a qual nos debruçamos neste artigo advém da pesquisa de campo, ao longo da qual não foi encontrado nenhum aparato de mediação que abordasse a cerveja enquanto bebida alcoólica, estando ausente qualquer abordagem da educação sobre drogas, sendo o uso dependente do álcool um dos maiores problemas de saúde pública no campo das drogas no Brasil. Essa inquietação surge mais precisamente motivada pela observação da sala de degustação de cerveja, pois quando ocorria a degustação, crianças e adolescentes que acompanhavam os responsáveis no tour eram proibidos de consumir cerveja. Diante do interdito etário surgia uma divisão no grupo familiar, divisando incluídos e excluídos do ritual do brinde. Dessa forma, os menores de 18 anos não podiam continuar a fazer parte da "brincadeira" destinada aos adultos, apesar de interagirem ao longo do percurso com seus responsáveis nos diversos aparatos.

Tendo em vista esse contexto, propomos apresentar a seguir os resultados da análise da cartilha Papo em família: como falar sobre bebidas alcoólicas com menores de 18 anos da Editora Maurício de Souza, distribuída no CECB. Será que a cartilha poderia responder questões que permaneceram em aberto ao longo da pesquisa, a saber: - por que os jovens não devem beber? Esta questão é analisada neste artigo por meio da análise do conteúdo. Buscamos, assim, problematizar os tensionamentos que justificassem a ausência de uma abordagem sobre o uso de drogas no percurso do tour cervejeiro, e mais especificamente, as limitações da cartilha de problematizar de forma crítica o uso do álcool. Os resultados 
apontam para o paradoxo da indústria da cerveja pelo qual interesses mercadológicos tensionam e são tensionados pelos dispositivos médico-legais no contexto de guerra às drogas.

\section{Questões de pesquisa: o interdito etário e o fim da brincadeira}

Antes de apresentar as questões de pesquisa é importante situar que essa, em escopo mais amplo, se desenvolveu no CECB, que pertence a uma empresa de capital aberto, líder no mercado latino-americano de cervejas com cerca de 70\% do market share no Brasil, sendo a cerveja a bebida alcoólica mais consumida no país. (CERVIERI JÚNIOR et al., 2014) O processo de internacionalização da Ambev teria se iniciado nos anos 2000, realizando, a partir de então, uma série de operações de internacionalização. Camargos e Barbosa (2005) apontam que a Ambev associada a Interbrew atua nos cinco continentes, formando a Interbrew Ambev. No mercado brasileiro, em 2015, a Ambev adquiriu microcervejarias como a Cervejaria Wäls e Colorado, o que demonstra o interesse da companhia em expandir sua atuação no segmento de cervejas especiais e diversificar sua produção. O CECB se localiza na cidade de Petrópolis sendo uma das menores unidades de produção cerveja da Ambev. A cervejaria Bohemia se volta à produção de cervejas especiais, possui interesse em atrair um público de maior renda que busca se distinguir pelo consumo de bens mais sofisticados.

Entendido como um espaço de divulgação da cultura cervejeira e de tecnologias de produção de cerveja, e portanto, de significados, o espaço possui cerca de nove salas de exposição interativas distribuídas em um percurso que dura em média uma hora e meia. As salas de visitação contam a história da cerveja e da cervejaria Bohemia na cidade de Petrópolis, os ingredientes e o processo de produção. A pesquisa de campo foi realizada durante cerca de três meses, nesse período foram realizadas 66 voltas completas pelo tour cervejeiro. O pesquisador atuava observando a dinâmica do percurso e utilizando um caderno de campo e uma máquina fotográfica (celular).

Ao longo da pesquisa foi possível observar o interesse de crianças e adolescentes no tour. O efeito das borbulhas de cerveja no chão da primeira sala chamava, especialmente a atenção das crianças que buscavam acertá-las com os pés. O vídeo acionado 
na sala do mestre cervejeiro contava a história da cervejaria se assemelhando a um conto infantil repleto de personagens. A sala dos ingredientes se destacava não apenas pelo aspecto visual como também era possível ouvir um som que reproduzia uma espécie de cascata de água, o barulho de um moinho de grãos e ainda a experiência do sensível relacionada ao gosto. Os grãos de cevada, trigo e aveia podiam ser provados girando a curiosa válvula que os liberava, estabelecendo relações com o cotidiano, como a aveia, que pode compor o desjejum de uma criança.

De acordo com o artigo segundo do Estatuto da Criança e do Adolescente - ECA (BRASIL, 1990), considera-se criança a pessoa até 12 de idade incompletos e como adolescentes a pessoa que possui entre 12 e 18 anos. Desde a primeira sala de visitação os grupos formados em grande parte por um perfil familiar (pais e/ou mães com filhas e filhos, avós e avôs, amigos a amigas) interagiam com seus pares diante dos aparatos, de modo que tanto as crianças como os adolescentes podiam compartilhar a experiência com os adultos. Crianças menores, ainda que não lessem, podiam apertar os botões e se interessar pela cenografia das salas, bem como toda sorte de imagens dos aparatos interativos expostos, o que nos leva a associar o espaço a um ambiente de diversão. Os familiares adultos pareciam se entusiasmar com a possibilidade interagirem com os menores como se encontrassem uma forma de entretê-los tornando a visitação mais interessante e aprazível.

O CECB se estrutura em diversos ambientes, além das salas de visitação do tour possui um bar, um restaurante e uma loja para venda de produtos. As principais salas de visitação são: a). sala saga da cerveja - ambiente com diversos aparatos interativos que contam a história da cerveja ao longo do tempo, da pré-história aos dias atuais, b) sala do mestre cervejeiro - sala com objetos históricos da antiga cervejaria Bohemia, nesta sala os visitantes assistem a um vídeo sobre a cidade de Petrópolis, a família imperial e a família Kremer, c) sala da alquimia - composta por antigos fornos de produção da cerveja não mais utilizados, representam a fase quente do processo de produção de cerveja, d) sala dos ingredientes - sala explicativa dos ingredientes que compõem a cerveja (água, cevada, lúpulo e fermento), e) sala da transformação - espaço com cenografia que remete a um ambiente futurista, ilustra a fase fria da produção de cerveja onde ocorre a primeira degustação, f) sala do ritual - espaço 
em formato de bar onde ocorre a segunda degustação de cerveja. Nas salas c, d e f ocorre a mediação guiada por monitores do CECB.

A questão que levou à análise da cartilha surgiu a partir das observações das salas onde ocorriam as degustações de cerveja. Após a apresentação dos monitores sobre o modo de produção de cerveja (sala da transformação) ocorria a abertura de uma porta secreta com uma chopeira repleta de taças cheias de cerveja intitulada "Bohemia da fonte", momento que funcionava como o ponto auge da visitação, ao menos para os maiores de 18 anos. A surpresa da abertura da fonte, no entanto, não incluiria os menores, uma vez que não podiam beber ou experimentar o exitoso ouro líquido repetidamente anunciado ao longo do percurso. Assim, comumente o entusiasmo que precedia o momento da degustação cedia lugar à decepção, pois nem todos participavam do brinde, que ocorria entre os adultos, surgindo uma espécie de partilha cindida pelo interdito etário.

Poderíamos supor que a interdição etária no momento da degustação poderia gerar certa incompreensão, sobretudo para os que não realizavam o brinde, exclusão que contrastava com a experiência que viam tendo ao longo do percurso, em que era possível participar de tudo, e mesmo experimentar, como no caso dos grãos que podiam ser provados na sala dos ingredientes. Como ao longo do percurso pelas salas de exposição não encontramos nenhuma abordagem sobre o uso de cerveja enquanto droga, nos voltamos à análise da cartilha da Ambev distribuída aos responsáveis de menores de 18 anos em visita ao local, quando assinavam um termo de compromisso declarando estarem cientes da proibição do consumo para menores de 18 anos.

Ao longo da pesquisa de campo no CECB, a cartilha foi encontrada pelo pesquisador por acaso, provavelmente esquecida por algum visitante em cima de um aparato na sala saga da cerveja, pois a cartilha era entregue apenas aos responsáveis de menores de 18 anos, de modo que não foi entregue ao pesquisador. A cartilha trouxe questões anteriormente não formuladas e que foram incorporadas à pesquisa, processo que demandou a análise de seu conteúdo a fim de compreender os tensionamentos inerentes a ausência de uma abordagem educativa sobre o uso do álcool nas salas de exposição. 


\section{A análise do conteúdo da cartilha}

A análise do conteúdo é um método utilizado para descrever e interpretar o conteúdo de documentos e textos variados, conduzida por descrições que contribuam à reinterpretação de mensagens e à compreensão de seus significados em um nível que esteja além de uma leitura comum. (MORAES, 1999) Como aponta Franco (2012), o ponto de partida da análise do conteúdo seria a mensagem, capaz de expressar um significado e um sentido que não podem ser considerados como um ato isolado, tornando-se indispensável observar que a emissão de mensagens está necessariamente articulada com as condições contextuais.

Assim, tomamos como ponto de partida Bardin (2011), cuja análise do conteúdo se organiza em torno de três momentos: a) pré-análise, b) exploração do material, c) tratamento dos resultados, inferência e interpretação. A pré-análise consistiu em operacionalizar e sistematizar as ideias iniciais começando por uma leitura flutuante da cartilha. A partir de então exploramos o material a fim de compreender a pergunta que ficou em aberto ao longo do percurso do CECB, afinal: - Por que os jovens não devem beber?

Dessa forma, recorremos a trechos da cartilha que tivessem relação com o objetivo de responder a questão posta, realizando inferências dialogadas com o aporte teórico da educação sobre drogas para a interpretação dos dados advindos de textos e imagens. Nossa hipótese girava em torno dos tensionamentos causados por dispositivos médico-legais no contexto do mercado de bebidas alcoólicas, em particular o de cerveja, no qual se situa a Ambev. Nesse processo se apresentou como uma limitação da pesquisa o volume de dados advindos do conteúdo da cartilha, sendo necessário a aplicação de recortes, escolhas e seleções a fim de compor o corpus, conjunto de documentos submetidos a processos analíticos.

\section{Educação sobre drogas: por que os jovens não devem beber?}

A cartilha distribuída pela Ambev no CECB aborda o álcool utilizando a imagem de personagens da Turma da Mônica, veiculada pela Editora Maurício de Souza que em 1996 lançou uma revista na qual também aborda o tema das drogas: Turma da Mônica: uma história que precisa ter fim. Com ampla tiragem, a revista foi 
traduzida em inglês e espanhol, utilizada como material didático pelo Programa Educacional de Resistência às Drogas e à Violência (PROERD). Sobre esse material, Acselrad e Alarcon (2014) apontam que, embora a revista seja destinada às crianças, com personagens que aparentam ter por volta de 6 e 7 anos, o conteúdo seria mais adequado ao cotidiano dos adolescentes, não trazendo informações sobre o processo de sua elaboração. Na capa, uma imagem que confunde gerando medo com personagens estereotipados como a imagem de um menino de óculos escuros que usa drogas e o traficante cabeludo com aparência alienígena, usando uma capa de inverno pesada onde guarda seringas, cigarros e frascos. Assim, sugere-se que "[...] no caso de um mau encontro (com o traficante), uma boa coelhada resolverá tudo até que a polícia chegue [...]. A linguagem do medo para se chegar à erradicação da droga e a sugestão de reagir com uma coelhada é ingênua." (ACSELRAD; ALARCON, 2014, p. 67)

A revista, utilizada pelo PROERD em escolas, estaria afinada com o modelo de prevenção e erradicação das drogas ilícitas com reduzida referência às bebidas alcoólicas, restrita a uma frase sobre acidentes de trânsito. A história descrita pela revista incorporaria um discurso baseado em uma legislação proibicionista transformada em política de governo a partir de acordos firmados por governantes em convenções internacionais a fim de concretizarem a política antidrogas: "diferenciaram de forma arbitrária as drogas em ilícitas e lícitas, privilegiando as primeiras na tentativa de sua erradicação. Ao álcool - usos e danos - restou um cuidado secundário". (ACSELRAD; ALARCON, 2014, p. 84)

Ainda que recorra aos personagens da Turma da Mônica e seja da mesma editora, a cartilha distribuída no CECB se volta às bebidas alcoólicas como mostra o título da capa: Papo em família: como falar sobre bebidas alcoólicas com menores de 18 anos. A proposta teria se baseado no manual - Como falar sobre o uso do álcool com seus fithos -, elaborado pelo Centro de Informações sobre Saúde e Álcool (CISA), uma Organização da Sociedade Civil de Interesse Público (OSCIP). O programa da cartilha seguiria as diretrizes da Organização Mundial da Saúde (OMS), desenvolvendo projetos como o Jovem responsa, o Supermercado responsa e o Bar responsa que visam estimular o consumo responsável. Assim, a Ambev "[...] se preocupou em ressaltar, para toda a sociedade, que seus produtos são destinados a momentos de celebração e descontração, e não 
podem jamais ser consumidos por menores de idade, em excesso ou associados à direção". (SOUSA, 2013, p. 39)

Então, se ao longo do percurso do CECB não estava posta a preocupação com uso da cerveja enquanto bebida alcoólica, que significados a cartilha atribuiria ao uso do álcool? Vejamos no trecho a seguir, como a cartilha responde a pergunta que surgiu como uma inquietação na pesquisa de campo no CECB: "Por que os jovens não devem beber?":

\footnotetext{
Os jovens não podem beber porque ainda não conhecem seus limites. Costumam ser muito imediatistas, o passado já passou e o futuro está muito longe, querem viver o presente a qualquer custo. Não conhecem os efeitos do álcool em seu corpo e não têm maturidade o suficiente para decidir adequadamente. Além disso, o efeito do álcool no organismo de um adolescente é diferente do efeito em um adulto. O sistema nervoso central ainda está em desenvolvimento, as vias neurais são mais suscetíveis. (SOUSA, 2013, p. 21)
}

No texto da cartilha "os jovens não podem beber porque ainda não conhecem seus limites", porque "costumam ser muito imediatistas" e "querem viver o presente a qualquer custo". A elaboração discursiva considera os jovens de forma genérica, não levando em consideração que cada adolescente é único em suas experiências e sua história de vida. Como entende Acselrad (2015), testar a consciência sobre si faz parte da experiência humana, sendo a adolescência um momento em que fazer coisas que seriam privilégio de adultos. Seria comum nessa idade enfrentar desafios e ter comportamentos de risco medindo a própria capacidade, de modo que as drogas representam uma das questões entre muitas outras com as quais os jovens se deparam na adolescência.

Em seguida, a cartilha discorre que os jovens "não conhecem os efeitos do álcool em seu corpo e não têm maturidade o suficiente para decidir adequadamente". Nesse sentido, conhecer os efeitos do álcool no corpo faz parte de um processo de aprendizado e socialização, como no princípio de carreira (BECKER, 2008), pois, para que o uso das drogas continue é preciso antes identificar seus efeitos como prazerosos. A frase da cartilha pode fazer sentido do ponto de vista legal, pois juridicamente os menores de 18 anos não respondem sozinhos pelas consequências de seus atos. 
Acselrad propõe a Educação para autonomia de Paulo Freire para pensar a educação sobre drogas. Vale lembrar que para Freire "ensinar exige riscos, a aceitação do novo e a rejeição a qualquer forma de discriminação". (FREIRE, 2013, p. 36) A relação entre educador e educando deve se dar por uma educação dialógica em um movimento dinâmico que evite a transmissão de saberes prontos e acabados, doados de um ao outro, pois "ensinar não é transferir conhecimento, mas criar as possibilidades para a sua própria produção ou a sua construção". (FREIRE, 2013, p. 47) A educação para autonomia exige a consciência do inacabamento dos saberes e o respeito à autonomia do saber do educando, sendo um processo permanente, no qual professor e aluno devem ser igualmente sujeitos na construção e reconstrução do saber.

Mas será, como indaga Acselrad (2014), que a maturidade para decidir adequadamente acometeria o jovem subitamente nos primeiros momentos do dia em que completa 18 anos? Na confusão entre o falso e o verdadeiro, poderiam os adolescentes supor, ao observar exemplos da vida, como na própria família, que a maioridade civil não garante o uso de drogas sem maiores danos. Ao tomar como referência o conto da Bela Adormecida do livro Doces venenos: conversas e desconversas sobre drogas de Aratangy (1991), não teria sido mais sábio se os pais tivessem explicado à filha o que são rocas/drogas ensinando-a a se proteger? Mas, não sabendo como lidar com as rocas/drogas, ao completar 15 anos, a princesa se fere e adormece para sempre.

Na última frase da citação de Sousa (2013, p. 21), a cartilha recorre a uma justificativa calcada nos saberes médicos, como a abordagem centrada nos efeitos da droga no corpo, restringindo a educação sobre drogas é informação biológica. Nesse sentido, Campos (2005) considera o desafio de abordar o tema das drogas, bem como a necessidade de se construir um conceito sobre drogas mais amplo. Da mesma forma que a informação biológica sobre a reprodução não define se alguém pode ou não ter relações sexuais, a farmacologia dos psicoativos não deveria responder quem deve ou não usar drogas, pois "[...] basear a educação sobre drogas na farmacologia é tão pseudoconcreto quanto basear educação sexual na biologia da reprodução". (CAMPOS, 2005, p. 214)

Em relação aos "adolescentes e o meio social" a cartilha coloca que "é importante deixar claro para eles que o normal é não consumir bebida alcoólica antes dos 18 anos. Os jovens que consomem bebidas 
1 Entrevista realizada por Drauzio Varella com Ronaldo Laranjeiras e Maurício de Souza Lima. Disponível em: https://drauziovarella.uol.com. br/entrevistas-2/alcoolismo-naadolescencia-entrevista/. Acesso em: 11 jun. de 2019. alcoólicas são uma minoria, e seu exemplo não deve ser seguido". (SOUSA, 2013, p. 15) Em uma perspectiva comportamentalista, o texto discorre que não seria normal consumir bebidas alcoólicas antes dos 18 anos, os que assim o fazem seriam uma minoria cujo exemplo não deve ser seguido, mas sim o comportamento daqueles que cumprem a lei e que, antes da maioridade civil, não consomem bebidas alcoólicas. A justificativa técnico-jurídica, assim como a ciência, são discursos comumente acionados para legitimar a proibição. Tratando como anormal o uso de bebidas alcoólicas antes da maioridade civil, a cartilha reforça o argumento legal e resguarda a empresa de dispositivos como o ECA.

A afirmação trazida pela cartilha de que entre os jovens seria uma minoria que faz uso de bebidas alcoólicas na adolescência contrasta com o resultado de pesquisas sobre o consumo de álcool pelos adolescentes no Brasil. Segundo Laranjeira e demais autores (2007, p.43), entre os adolescentes de 14 a 17 anos 75\% são abstinentes, entendidos como aqueles que não consumiram álcool nos últimos 12 meses antes da pesquisa, ao passo que os não abstinentes, que fizeram uso nesse período, correspondem a $25 \%$, ou seja, embora o percentual de abstinentes se reduza na idade adulta, o consumo de bebidas alcoólicas entre os adolescentes não deve ser negligenciado tampouco tomado como um consumo de minoria.

Ademais, como observa Ronaldo Laranjeira, um dos organizadores do primeiro e do segundo levantamento supracitado, e Maurício Lima, ${ }^{1}$ o consumo de bebidas alcoólicas entre os adolescentes no Brasil tem se apresentado preocupante. Os pais permitiriam aos filhos beber porque não veem perigo na bebida sob a justificativa de que todos os adolescentes bebem, o que contribui para que se comece a beber cada vez mais cedo. Atualmente, seria comum entre os adolescentes o "esquenta", quando se reúnem em casa a fim de se preparem para chegar alcoolizados nas festas. No Brasil, o consumo regular na adolescência ocorreria por volta dos 14 anos, de modo que muitos pais consideram normal que os garotos bebam grandes volumes nessa idade. Como fatores contribuintes estaria a propaganda dirigida ao público jovem com os produtos desenvolvidos especialmente para essa faixa etária, além do baixo preço da bebida, o fácil acesso, a precária fiscalização e a ausência de controles sociais. Dessa forma, a depender do contexto, é bem provável que o desviante, no caso de um "esquenta", seja o 
adolescente que opte por não fazer uso de bebidas alcoólicas, o que requer pensar em ações educativas que falem abertamente sobre as drogas, sem relegar ao álcool um papel secundário.

Algumas vezes na degustação, de forma tímida, a cerveja podia ser oferecida pelos responsáveis ao adolescente, seja como uma forma de incluí-lo ou mesmo em função de uma ação que se pretendesse educativa. O oferecimento era normalmente negado, o que nos sugere uma reação de negação ao rótulo da conduta desviante, mesmo que para molhar o "bico" e saber o gosto que tem. Talvez não fosse naquele momento - sob os holofotes familiares -, do espetáculo idílico dos adultos, que o adolescente faria a experimentação, podendo fazê-la quiçá em outras situações mais estimulantes como entre amigos e outros afetos, testando as fronteiras sem que the seja impresso o rótulo de desviante. A ideia de uma normalidade pressupõe a de um desvio, sendo que "o desvio não é uma qualidade do ato que a pessoa comete, mas uma consequência da aplicação por outros de regras e sanções a um infrator". (BECKER, 2008, p. 22)

Dessa forma, o discurso da cartilha considera como desviante o menor que faz uso de cerveja, o que apontamos como um paradoxo no contexto analisado tendo em vista que durante a maior parte do percurso do tour cervejeiro no CECB a cerveja é glamourizada, o que não ocorre da mesma forma no momento da degustação, quando o interdito etário se apresenta de forma impositiva sem explicações aparentes.

\section{As limitações do paradoxo da indústria da cerveja: os dispositivos médio legais}

Como resultado, a pesquisa sugere a existência de um paradoxo da indústria da cerveja, termo cunhado em alusão ao dispositivo das drogas apresentado por Vargas (2011), quando discorre sobre o paradoxo das drogas de nosso tempo. Vargas critica a forma como de um lado se condena e pune o uso de algumas substâncias - associadas ao estigma do vício e da doença - como as drogas (tornadas) ilícitas, ao passo que nunca se incitou tanto o uso de outras, como as que advém da invasão farmacêutica. O paradoxo das drogas é o que pretendemos abordar nesse tópico, recorrendo a dois dispositivos médico-legais, que ao mesmo tempo inibem a atuação da indústria da cerveja no consumo de bebidas alcoólicas, 
e são permissivos com a propaganda, o que se apresenta como uma limitação da educação sobre drogas, sobretudo, a partir da abordagem da redução de danos.

Como propõe Acselrad (2005), a educação sobre drogas pensada a partir da educação para a autonomia de Paulo Freire dialoga com as políticas e práticas de Redução de Danos (RD). Nessa perspectiva, a RD não impõe a abstinência por reconhecer que a decisão do uso se dá no âmbito privado, o que não implica pregar a permissividade, mas compreender que educar para autonomia requer se desfazer da pretensão de impedir a experiência do uso, buscando tornar o indivíduo capaz de reflexão e ação protetora de si e de seu entorno.

Adotando uma perspectiva comportamentalista pautada na abstinência, a cartilha acena de forma tímida para abordagens que poderiam reduzir danos como o beber pesado em um único episódio - binge drinking -, o que ocorre com uma média de acúmulo de 50 g a 60 g de álcool no organismo. Para determinação do beber seguro, foram criados parâmetros médicos, a partir do conceito de unidade de álcool que significa a ingestão de aproximadamente 10 g de álcool puro, quantidade que varia de acordo com a bebida, sendo de modo geral obtida por um copo de $250 \mathrm{ml}$ de cerveja, uma taça de vinho de $90 \mathrm{ml}$ ou uma dose de destilado de $25 \mathrm{ml}$. (ALARCON, 2012) Entretanto, a cartilha não aborda os diferentes tipos de uso de drogas, como o esporádico, o recreativo, o social, o abusivo ou o uso nocivo, tampouco a intensidade de uso do álcool como: bebedor frequente pesado, bebedor frequente, bebedor menos frequente, bebedor não frequente e abstêmio.

A limitação tanto do CECB quanto da cartilha em avançar na construção de um conhecimento sobre drogas pautado na autonomia se apresenta diante de dispositivos médico-legais como o Estatuto da Criança e do Adolescente (ECA). O artigo 243, da Lei nº 8.069 do ECA (1990) estabelece que é proibido "vender, fornecer, servir, ministrar ou entregar, ainda que gratuitamente, de qualquer forma, à criança ou ao adolescente, bebida alcoólica ou, sem justa causa, outros produtos cujos componentes possam causar dependência física ou psíquica" (BRASIL, 1990), tendo como previsão de pena a "detenção de 2 (dois) a 4 (quatro) anos, e multa, se o fato não constituir crime mais grave". Diante desse dispositivo as ações pedagógicas acabam por evitar abordagens como a redução de danos, que podem soar como um incentivo ao uso de bebidas alcoólicas, 
já que falar sobre os usos de forma aberta, ou seja, trazer todo conhecimento que a ciência dispõe, levaria a se admitir ao contrário do que prevê o dispositivo médico-legal do ECA, que o adolescente poderá fazer uso ou faz uso.

Na cartilha, a abordagem sobre o uso de bebidas alcoólicas é reduzida ao considerar dois tipos de uso: o "consumo em pequenas quantidades" e o "consumo em excesso", que se daria a partir da ingestão de cinco doses "quando é preciso pedir ajuda" e "tratamento". (SOUSA, 2013, p. 36-37) Como apontada por Silva e Delduque (2015) existe uma confusão semântica entre os termos "uso", "abuso" e "dependência", não apresentada pela cartilha ao adotar um discurso que se assenta em uma visão dicotômica do consumo reforçando a ideia segundo a qual o consumo em excesso em um único episódio de uso poderia levar ao abuso e à dependência, abordagem que tende à patologização do uso e do usuário.

A cartilha seguiria as orientações para as diferentes faixas etárias apoiadas no Modelo Éduc'alcool/CISA + Family Talk Guide Anheuser - Busch Inbev. (SOUSA, 2013, p. 30) Nas últimas páginas se observa a imagem de um adulto que lembra a de um professor ou palestrante, que em uma espécie de sala de aula, situada entre a logomarca da Organização Mundial de Saúde (OMS) e a expressão "Consumo responsável". A referência à OMS parece, assim, se apresentar mais em função de conferir legitimidade científica à cartilha do que prevenir danos e evitar riscos.

A divisão entre drogas lícitas e ilícitas se refere à existência de uma partilha moral de ordem médico-legal que aponta a contradição do que Vargas (2011) entende como "dispositivo das drogas". Diante dessa partilha, a cartilha se esforça para ocultar que as bebidas alcoólicas são drogas, sendo o uso dependente do álcool o principal problema de saúde pública no campo das drogas no Brasil, ainda que se considere a possibilidade de uma subnotificação do uso de drogas ilícitas.

Como considera Campos (2005), embora as drogas sejam tidas como elementos patológicos da sociedade são, na realidade, elementos dela constituintes, sendo patológico ou não, a relação que as pessoas estabelecem com as drogas. A droga mais perigosa é aquela com a qual se tem um uso problemático ou que se desconhece a toxicidade, de modo que o uso de qualquer droga possui riscos, não estando o problema da droga na substância em si, mas relacionada a um conjunto de fatores como a personalidade, o 
produto, o meio e o momento em que se vive. (ACSELRAD, 2015) Para Alarcon (2015), cada indivíduo em um contexto particular reage de forma diferente à droga, o que hoje pode ser considerado leve, amanhã pode se tornar pesado para a mesma pessoa, sendo que quem experimenta uma droga pela primeira vez ou mesmo quem a usa habitualmente pode não ter maiores problemas se o uso não comprometer as suas atividades, seus afetos, seu trabalho, enfim, sua vida em geral.

As drogas mais usadas e as que causam mais dependência no país são as de uso tolerado, o álcool e o tabaco, de modo que diferente do tabaco, do vinho e dos destilados, a cerveja goza de um lugar privilegiado nas restrições à propaganda na Lei no 9.294/1996. Segundo Karam (2014), enquanto para o tabaco existem cláusulas para advertência de seus males nos rótulos com imagens aterrorizadoras, para as bebidas alcoólicas a lei determina que as embalagens contenham somente a frase "evite o consumo excessivo do álcool", sem qualquer advertência aos riscos e danos à saúde. A mesma lei que estabelece ser vedada a propaganda comercial de derivados do tabaco permite a propaganda comercial de bebidas alcoólicas em emissoras de rádio e televisão, com restrição ao horário de $21 \mathrm{~h}$ às 6h, prevendo ainda a não associação do produto ao esporte ou a qualquer atividade de desempenho saudável. O mais inexplicável, contudo, seria a exclusão das cervejas no que a referida lei entende por bebidas alcoólicas, uma vez que as restrições incidem apenas sobre as bebidas que contenham teor alcoólico superior a 13\% do volume, definição que exclui as cervejas cujo teor alcoólico gira em torno de $5 \%$.

Ainda que a indústria da cerveja produza ações educativas sobre o uso de seus produtos, como no projeto da cerveja Brahma + ID e Regra é clara, menor de idade não pode beber, estrelada pelo ex-jogador Cafu, chegando a doar 100 mil aparelhos de bafômetros ao poder público (SOUZA, 2013), a veiculação da propaganda associa a cerveja ao esporte e a figuras públicas do meio artístico. Como mostra a pesquisa de Silva (2012) estratégias de marketing como as da Ambev na campanha "Chegou Skol $360^{\circ}$ graus", de 2011, podem ser fruto de três anos de pesquisa, nesse caso, a fim de levar ao mercado uma cerveja que "não estufa e que desce redondo". A marca de cerveja Skol está entre as três mais valiosas do país, como mostra a pesquisa da Interbrand que classifica o valor de mercado das marcas. Entre as 25 marcas mais valiosas do 
mercado brasileiro estão em primeiros e segundo lugar os bancos Itaú e Bradesco, respectivamente, e em terceiro lugar a cerveja Skol que pertence a Ambev. ${ }^{2}$

Em suma, o paradoxo da indústria da cerveja se apresenta como um limitador da educação sobre drogas nas ações formais do CECB e na cartilha analisada, pois a Ambev responde aos tensionamentos médico-legais oscilando entre a proibição e a permissividade do uso do álcool, estando esses dispositivos em constante negociação.
2 Ranking das marcas brasileiras mais valiosos em 2019 segundo a Interbrand. Disponível em: https:// www.interbrand.com/br/bestbrands/best-brazilian-brands/2019/ ranking/. Acesso em: 7 abr. 2020.

\section{Considerações finais}

Como vimos, no percurso do CECB, o visitante que possui mais ou menos de 18 anos, não importa, estaria imerso em um contexto no qual se glamouriza a cerveja e seu uso sem nenhum aparato, entre tantos, que abordasse os riscos inerentes ao uso, que embora sejam pequenos no caso de se tornar um uso problemático, existem e não devem ser negligenciados, sendo o uso dependente de álcool um dos principais problemas de saúde pública no campo das drogas no Brasil. Nesse caso, o maior risco seria não abordar o álcool enquanto droga, perdendo a educação sobre drogas a possibilidade de realizar uma abordagem ampliada na qual não se demonize o uso de drogas, uma vez que é parte constituinte da cultura.

Nesse cenário, se apresenta o paradoxo da indústria da cerveja com tensionamentos em constante negociação entre os interesses mercadológicos e os dispositivos médico-legais. Se, por um lado nas ações formais a Ambev adota uma dimensão proibicionista, por outro, o uso é incitado pelas estratégias da propaganda, sem que nesse caso se evidencie a mesma preocupação para que os jovens não bebam. Uma abordagem que considere que menores de 18 anos fazem uso ou podem fazer uso de bebidas alcoólicas requer pensar a dimensão complexa da "drogalidade" e a impossibilidade de respostas prontas. Entretanto, adotar uma abordagem educativa que considere a existência do uso de drogas por menores de 18 anos poderia soar como um incentivo ao uso, resguardando-se a Ambev de incorrer em penalidades legais, bem como a prejuízos mercadológicos, por meio de uma abordagem menos problematizadora sobre o uso do álcool.

Enfim, a ausência de qualquer abordagem no percurso do CECB sobre a cerveja enquanto droga se reflete também na cartilha, 
como se fosse preciso assegurar que a cerveja continue a ser percebida como uma bebida diferente das demais. Assim, a cerveja continuaria situada distante do perigo que representa as drogas ilícitas, consideradas duplamente drogas, o que reforça a dicotomia do imaginário sobre as drogas lícitas e ilícitas que beneficia a indústria da cerveja no contexto da política de guerra às drogas. Dessa forma, estaria prescrita a fórmula da ação proibicionista que responde aos tensionamentos entre os interesses mercadológicos e os dispositivos médico-legais, perdendo tanto os maiores, quanto os menores de 18 anos, a oportunidade de conhecer mais sobre drogas para se proteger.

\title{
Drug education and the limitations in the paradox of the beer industry
}

\begin{abstract}
This research is based on a rereading of drug education, in order to problematize the limitations to this approach on educational strategies of the beverage industry, more specifically the beer industry. In a larger spectrum, the research has been developed on the Center of Experience of the Bohemia Brewery (CECB), which is a part of the American Drinking Company (Ambev), located on Petrópolis, in Rio de Janeiro state. The objective of this paper is to analyze the booklet called Family talk: how to talk about alcoholic drinks with underaged people, that has been given to the parents of underaged teenagers during a visitation to the CECB. The topic we had been studying about is how to comprehend the mechanisms that interfere on the production of meaning about te use of alcohol in this booklet, and its relation to drug education under the perspective of autonomy, pursuing to identify the mechanisms that act on the limitation of this approach. As a result, it is suggested the existence of a paradox in the beer industry, in which on the one hand, AMBEV stimulates the use of alcohol, and on the other hand, it addopts a prohibitionist approach, what happens due to a tension between market interests and legal-medical mechanisms, nurtured by the war on drugs policy.
\end{abstract}

Key-words: drug education; beverage industry; beer; alcohol; medical-legal mechanisms.

\section{La educación sobre drogas y las limitaciones de la paradoja de la industria de la cerveza}

\footnotetext{
Resumen: Este estudio se basa en una relectura de la educación sobre drogas para problematizar las limitaciones de este enfoque en las estrategias educativas sobre el uso de alcohol en la industria de bebidas, más específicamente, la industria de la cerveza. En un ámbito más amplio, la investigación se desarrolló en el Centro de Experiência Cervejeira da Bohemia (CECB), que pertenece a la Compañía de Bebidas de las Américas (Ambev), ubicado en la ciudad de Petrópolis, en el estado de Río de Janeiro. El propósito de este artículo fue analizar el folleto Conversación en Familia: cómo hablar sobre
} 
bebidas alcohólicas con menores de 18 años, distribuido entre los responsables de menores de 18 años que visitaban el recorrido por la cervecería CECB. El tema que nos preocupa se refiere a la comprensión de los dispositivos que interfieren en la producción de significados sobre el uso de alcohol en el folleto y su relación con la educación sobre drogas desde la perspectiva de la autonomía, buscando identificar los dispositivos que actúan para limitar este enfoque. Como resultado, sugerimos la existencia de una paradoja en la industria de la cerveza en la que, por un lado, Ambev fomenta el uso de alcohol, y por otro, adopta un enfoque prohibicionista debido a la tensión entre los intereses del mercado y los dispositivos médico-legales. De esta forma la política de guerra contra las drogas se retroalimenta.

Palabras chave: educación sobre drogas; industria de bebidas; cerveza, alcohol; dispositivos médico-legales.

\section{Referências}

ACSELRAD, G. Estado do conhecimento sobre o consumo de bebidas alcoólicas no Brasil. In: ACSELRAD, G. (org.). O consumo do álcool no Brasil. FLACSO Brasil: Rio Janeiro, jul. 2014. p. 8-24. (Série Cadernos FLACSO, n. 12).

ACSELRAD, G. A Educação para autonomia: construindo um discurso democrático sobre as drogas. In: ACSELRAD, G. (org.) Avessos do prazer: drogas, Aids e direitos humanos. 2. ed. Rio de Janeiro: Fiocruz, 2005. p. 183-212.

ACSELRAD, G. Quem usa? O que usa? E por que usa? In: ACSELRAD, G. (org.). Quem tem medo de falar sobre drogas? Saber mais para se proteger. Rio de Janeiro: FGV, 2015. p. 15-30.

ACSELRAD, G.; ALARCON, S. Políticas públicas atuais sobre bebidas alcoólicas. In: ACSELRAD, G. (org.). O consumo do álcool no Brasit. FLACSO Brasil: Rio Janeiro, 2014. p. 60-84. (Série Cadernos FLACSO, n. 12)

ALARCON, S. Drogas... que efeito isso tem? In: ACSELRAD, G. (org.). Quem tem medo de falar sobre drogas? Saber mais para se proteger. Rio de Janeiro: FGV, 2015. p. 47-58.

ARATANGY, L. Doces venenos: conversas e desconversas sobre drogas. São Paulo: Olho d'Água, 1991.

BECKER, H. S. Outsiders: estudos de sociologia do desvio. Tradução de Maria Luiza X. de Borges. Rio de Janeiro: Zahar, 2008.

BARDIN, L. Análise de conteúdo. Lisboa: Edições 70, 2011.

BRASIL. Lei n. 8.069, de 13 de julho de 1990. Dispõe sobre o Estatuto da Criança e do Adolescente e dá outras providências. Brasília, DF: Presidência da República, Casa Civil Disponível em: http://www. planalto.gov.br/ccivil_03/leis/18069.htm. Acesso em: 11 jun. 2019.

CAMARgOS, M. A. de; BARBOSA, F. V. Caderno de Pesquisas em Administração, São Paulo, v. 12, n. 2, p. 99-115 abr./jun. 2005. 
CAMPOS, M. A. Freire e Freud: por uma atitude transitiva na educação sobre drogas. In: ACSELRAD, G. (org.). Avessos do prazer: drogas, aids e direitos humanos. 2. ed. Rio de Janeiro: Fiocruz, 2005. p. 213-230.

CERVIERI JÚNIOR, O.; TEIXEIRA JÚNIOR, J. R.; RANGEL, G.; RAWET, E. L.; SILVEIRA, C. T. J. da. O setor de bebidas no Brasil. BNDES Setorial. Rio de Janeiro, n. 40, set. 2014.

FREIRE, P. Pedagogia da autonomia: saberes necessários à prática educativa. 47. ed. Rio de Janeiro: Editora Paz e Luz, 2013.

FRANCO, M. L. P. B. Análise de conteúdo. 4. ed. Brasília, DF: Liber Livro Editora, 2012.

KARAM, M. L. Os principais aspectos da legislação brasileira relacionadas às bebidas alcoólicas In: ACSELRAD, G. (org.). O consumo do álcool no Brasil. FLACSO Brasil: Rio Janeiro. 2014. p. 40-46. (Série Cadernos FLACSO, n. 12).

LARANJEIRA, R.; PINSKY, I.; ZALESKI, M.; CAETANO, R. I Levantamento nacional sobre os padrões de consumo de álcool na população brasileira. Brasília, DF: Secretaria Nacional Antidrogas, 2007.

MORAES, R. Análise de conteúdo. Revista Educação, Porto Alegre, v. 22, n. 37, 1999.

SILVA, M. B. e S.; DELDUQUE, M. C. Patologização e penalização do uso de drogas: uma análise socioantropológica de proposições legislativas.

Physis Revista de Saúde Coletiva. Rio de Janeiro, v. 25, n. 1, Rio de Janeiro, jan./mar. 2015.

SILVA, S. A persuasão na propaganda de cervejas: sob o enfoque sistêmico-funcional. Dissertação (Mestrado em Linguística Aplicada e Estudos de Linguagem) - Pontifícia Universidade Católica de São Paulo, São Paulo, 2012.

SOUSA, M de. Papo em família: como falar sobre bebidas alcoólicas com menores de 18 anos. São Paulo: Editora Maurício de Sousa, 2013. Realização: Ambev - Companhia de Bebidas das Américas. Apoio científico. Centro de Informações sobre Saúde e Álcool (CISA).

VALENTE, M. E. A. Museus de ciências e tecnologia no Brasil: uma história da museologia entre as décadas de 1950-1970. 2009. Tese (Doutorado em Ensino e História de Ciências da Terra) - Instituto de Geociências, Universidade Estadual de Campinas, Campinas, 2009.

VARGAS, E. V. Entre a extensão e a intensidade: corporalidade, subjetivação e uso de drogas. 2001. Tese (Doutorado em Ciências Humanas, Sociologia e Política) - Faculdade de Filosofia e Ciências Humanas, Universidade Federal de Minas Gerais, Belo Horizonte, 2001.

Submetido em 07/04/2020.

Aceito em 22/04/2020. 